\title{
The effect of surface characteristic of sand for denitrification and calcium carbonate mineralization on the surface
}

\author{
AKIKO NAKANO \\ Kyushu University \\ Presenting Author: nakiko@agr.kyushu-u.ac.jp
}

Microbial induced desaturation and precipitation (MIDP) is one of the process for soil improvement by denitrification and the following carbonate precipitation applied in water saturated sandy soils. The reaction and its effect were surely confirmed in natural sea sand [1]. However, denitrification never proceeded in artificially crushed silica sand. The surface characteristics of natural sands are not homogenous in view of micro- or nanoscale surface condition. And the variations will be controlling the microbial activity for denitrification. The specific surface area produced by trace small minerals like clay and metal hydroxides and oxides on the bigger particles like quartz in sand will be required to accumulate bacterial cells and improve their activity. Also, such the surface environment is helping nucleation to produce calcium carbonate crystals on the surface. This study shows the surface potential measurement of natural sand with various surface conditions and examines the effect of the sand surface characteristic to improve MIDP process (Figure 1).

[1] Nakano, A. (2018). Géotechnique Letters 8, 1-4.

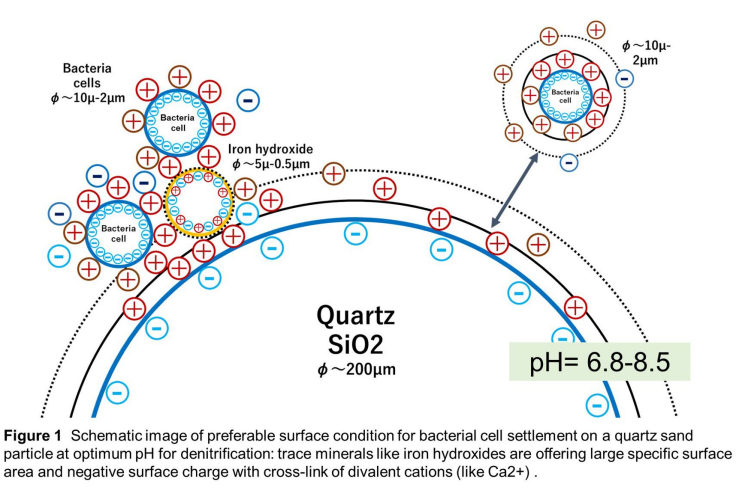

